\title{
Liquidus Tracking:
}

\section{Large scale preservation of encapsulated}

\section{3-D cell cultures using a vitrification machine}

\author{
Eva Puschmann ${ }^{\mathrm{a}^{*}}$, Clare Selden ${ }^{\mathrm{a}}$, Steve Butler ${ }^{\mathrm{b}}$ and Barry Fuller \\ ${ }^{\mathrm{a}}$ UCL, Institute for Liver \& Digestive Health, Royal Free Campus, London, NW3 2PF, UK \\ ${ }^{\mathrm{b}}$ Planer PLC,110 Windmill Road, Sunbury-on-Thames, UK \\ ${ }^{c}$ UCL, Department of Surgery, Royal Free Campus, London, NW3 2PF, U.K. \\ For correspondence: eva.puschmann.10@ucl.ac.uk
}

\begin{abstract}
Currently, cryo-banking of multicellular structures such as organoids, especially in large volumes at clinical scale $>1$ litre, and large volumes remains elusive for reasons such as insufficient dehydration and cryoprotectant additive $\left(\mathrm{CPA}^{1}\right)$ penetration, slow cooling and warming rates and devitrification processes. Here we introduce the concept of Liquidus Tracking (LT) using a semi-automated device for liquid volumes of up to $450 \mathrm{ml}$ including $130 \mathrm{ml}$ of alginate encapsulated liver cells (AELC) that archived controlled and reversible vitrification with minimized toxicity.
\end{abstract}

First a CPA solution with optimal properties for LT was developed by employing different small scale test systems. Combining sugars such as glucose and raffinose with $\mathrm{Me}_{2} \mathrm{SO}$ improved post-exposure $\left(\right.$ at $+0.5^{\circ} \mathrm{C}$ ) viabilities from $6+/-3.6 \%$ for $\mathrm{Me}_{2} \mathrm{SO}$ alone up to $58+/-$ $6.1 \%$ and $65+/-14.2 \%$ respectively $(\mathrm{p}<0.01)$. Other permeating CPAs (e.g. ethylene glycol, propylene glycol, methanol) were investigated as partial replacements for $\mathrm{Me}_{2} \mathrm{SO}$. A mixture

\footnotetext{
${ }^{1}$ cryoprotectant additive (CPA), Liquidus Tracking (LT), alginate encapsulated liver cells (AELC), alpha-fetoprotein (AFP), mixture of $\mathrm{Me}_{2} \mathrm{SO}$, ethylene glycol and glucose (ratio 4:2:1): termed LTdeg.
} 
of $\mathrm{Me}_{2} \mathrm{SO}$, ethylene glycol and glucose (ratio 4:2:1- termed LTdeg) supported glass-forming tendencies with appropriate low viscosities and toxicities required for LT. When running the full LT process, using $\mathrm{Me}_{2} \mathrm{SO}$ alone, no viable cells were recovered; using LTdeg, viable recoveries were improved to $40+/-8 \%$ ( $\mathrm{p}<0.001 \%)$. Further refinements of improved mixing technique further improved recovery after LT. Recoveries of specific liver cell functions such as synthesis of albumin and alpha-fetoprotein (AFP) were retained in post thaw cultures. In summary: By developing a low-toxicity CPA solution of low viscosity (LTdeg) suitable for LT and by improving the stirring system, post-warming viability of AELC of up to 90\% and a AFP secretion of $89 \%$ were reached. Results show that it may be possible to develop LT as a suitable cryogenic preservation process for different cell therapy products at large scale.

\section{Keywords}

Liquidus Tracking, large volume vitrification, CPA toxicity, Bioartificial liver device

\section{Introduction}

Scientists have successfully cryopreserved a variety of cells over the last 40 years, but success has mainly been achieved by traditional slow cooling with cell suspensions in small $(<10 \mathrm{ml})$ volumes $[16,45]$ in tube format, or in bag format in volumes of up to $200 \mathrm{ml}[10,17,33]$. Cooling multicellular systems down to deep sub-zero temperatures has proven far more challenging, especially when large volumes of biomass require cryo-banking. These problems began to be understood during early attempts to cryopreserve whole organs or large complex tissues. They were mainly related to the formation of extracellular ice in liquid spaces within the tissue [37], such as within small capillary blood vessels inside an organ [19], which physically destroyed the internal structure. In addition, disruptive ice propagation between inter-connected cells [1], insufficient cell dehydration and CPA penetration during slow

47 cooling and ice-recrystallization during the warming process have all been noted. These can 
also make cell agglomerates more susceptible to freezing damage than individual cells. Ice formation can be avoided by vitrification, but high cooling rates must frequently be imposed to avoid toxic effects from the essentially high CPA concentrations required and to maximise the likelihood of achieving the glassy state without ice nucleation events [13]. This remains a significant challenge for large tissues or, equally, for large volumes of functionally interconnected cells such as cell spheroids, as enough time must be given for CPA to penetrate into the all the cells, including those in the core, and for the core cells to dehydrate sufficiently to avoid intracellular freezing, risking toxic effects during CPA exposure and cooling. CPA toxicity is also critical during the warming process when high concentrations of CPAs will be present when the cryogenic glasses begin to liquefy; equally the high warming rates needed to prevent devitrification and ice re-crystallisation for all cells within a sample are difficult to achieve in large volumes [6,7]. Many of those obstacles can be overcome by Liquidus Tracking (LT), a method of achieving vitrification in an aqueous mixture by incrementally increasing concentrations of penetrating CPAs (up to $70 \%$ ) at incrementally decreasing temperatures $[15,38,47]$. Cryoprotectants are known to be less toxic at lower concentrations, but also at lower temperatures $[34,48]$ due to decreased cell activity, reduced chemical interaction with sensitive biomolecules and reduced CPA permeation. Due to reduced CPA toxicity, and avoidance of ice nucleation in LT, large samples can be vitrified without the necessity of fast cooling rates, or when longer exposure times are required to allow for sufficient CPA penetration - for example for organ and tissue vitrification.

69 We have previously studied cryopreservation by slow cooling of alginate encapsulated multicellular liver cell spheroids (AELC) in developing a bioartifical liver support system

71 [31]. Treatment volumes of between 1-2 litres of AELC for use in a bioartificial liver device have been used in our pre-clinical studies [11] and are predicted to be needed for patient 
therapy. We have also shown that LT vitrification can be applied to AELC in a small volume feasibility study [40]. Our aim here was to develop a LT protocol, which would allow the cryo-banking and warming of large volumes of AELC whilst maintaining good functional recovery. To improve cell viability we have developed a low-toxicity CPA solution for LT with the requirement of low viscosity (but which - nevertheless - could suppress ice nucleation) so that it may be used within the Liquidus Tracker equipment. Additionally the development of a new stirring system substantially increased post-warming viability.

\section{Materials and Methods}

Unless otherwise stated, all chemicals were sourced from Sigma (Poole, United Kingdom) and for cooling and warming a PlanerLiquidus Tracker Controller and a Controlled Rate Freezer (Planer, Kryo 10, Series II chamber) was used. CPA concentrations were used and reported in weight per volume $(\mathrm{w} / \mathrm{v})$ throughout this work.

\section{Cell culture and encapsulation}

The techniques for culturing HepG2 cells and producing AELC have been described previously in detail [11]. In brief: Confluent HepG2 monolayer cells (from ECACC, Wiltshire, UK) were encapsulated into $1 \%$ alginate (alginic acid sodium salt Macrocystis pyrifera kelp) by calcium-related polymerisation and cultured for $>11$ days until containing several thousand cells in spheroids within each alginate bead (average diameter $450 \mu \mathrm{m}$ ).

\section{Cell culture to different end cell densities}

92 For experiments that required different cell densities, AELC were cultured for either 3, 5, 7, 9

93 or 11 days before being used for LT.

\section{$94 \quad$ Viability assay}

95 Cell viability was measured by dual staining with fluorescein diacetate and propidium iodide using an established imaging software method for quantification which has been established 
against cell number and protein production [21]. Viability was measured after 24 hours posttreatment, the time point of lowest viability before on-set of recovery [31].

\section{Quantification of cell numbers}

100 Cell number quantification using the Nucleoview System (Sartorius Stedim, Epsom, United

101 Kingdom) has been described previously in detail [11]. Viable cell numbers were calculated

102 by multiplying the cell number by the viability for each sample.

103 Functional assays to assess protein synthesis by alpha-fetoprotein and albumin secretion

104 Alpha-fetoprotein (AFP) and albumin synthesis and secretion were measured by sandwich enzyme-linked immunosorbent assay which has been described previously in detail [11].

\section{Viscosity assessment and measurement}

107 Viscosity of CPA mixtures is an important factor in applying LT to facilitate good mixing

108 and ensure uniform high CPA concentrations to avoid ice nucleation. Viscosity of CPA

109 solutions was assessed for applicability by comparing new CPA solutions against a reference solution $\left(70 \%(\mathrm{w} / \mathrm{v}) \mathrm{Me}_{2} \mathrm{SO}\right)$ by observational grading of resistance to pipetting or to

111 manually stirring the solution at $-40^{\circ} \mathrm{C}$ - the lowest workable LT temperature from previous

112 experience [40]. For pipetting a standard $1 \mathrm{ml}$ Eppendorf pipette and $1 \mathrm{ml}$ pipette tips and for

113 stirring a stainless steel spatula with a $4 \mathrm{~mm}$ width were used. $10 \mathrm{ml} \mathrm{CPA}$ in $15 \mathrm{ml}$ Centrifuge tubes (Falcon, Fisher Scientific) were cooled to $-40^{\circ} \mathrm{C}$. This test was developed as no viscometers or rheometers operable at $-40^{\circ} \mathrm{C}$ were available locally and it also allowed direct rapid assessment of multiple samples. Viscosity was rated 1-4 $(1=$ similar to $70 \%(\mathrm{w} / \mathrm{v})$

$117 \mathrm{Me}_{2} \mathrm{SO}$, easy to pipette; 2 = pipetting not possible but can be easily stirred, $3=$ very viscous,

118 stirring very difficult, $4=$ stirring not possible, almost a solid). Solutions with a viscosity

119 rating of " 2 " were modified by replacing $10 \%$ of the highly viscous CPAs with less viscous

120 CPAs. In particular methanol was selected as a low viscosity CPA to reduce the overall

121 viscosity of the mixture. Thereafter, viscosities of the most promising CPA solutions were 
measured at $20^{\circ} \mathrm{C}$ using a Bohlin $\mathrm{CVO}$ automated shear rheometer to provide a set of

123 reference data. Shear stress $\left(\mathrm{s}^{-1}\right)$ was increased by 10 rpm every 10 seconds, from 10 to $124250 \mathrm{rpm}$.

\section{CPA toxicity tests}

126 A two-step protocol was used to reduce potential CPA-related osmotic injury based on

127 previous experience with AELC which have shown high viabilities after one step addition 128 and dilution of up to $40 \% \mathrm{Me}_{2} \mathrm{SO}(\mathrm{v} / \mathrm{v})$ [40]. A volume of $0.25 \mathrm{ml}$ settled beads (AELC) was 129 incubated in a 30\% (w/v) CPA solution for five minutes at room temperature (Falcon tubes, 130 Fisher Scientific), then for five minutes at $0.5^{\circ} \mathrm{C}$ (tubes in ice-water). The concentration was 131 then increased to $60 \%(\mathrm{w} / \mathrm{v}) \mathrm{CPA}$ and beads incubated for 10 or 20 minutes at $0.5^{\circ} \mathrm{C}$. CPA 132 concentration and incubation time were chosen to display strong difference in survival 133 between solutions. By adding 1xPBS for dilution steps, the CPA concentration was reduced 134 to $30 \%(\mathrm{w} / \mathrm{v})$. Samples were left on ice for five minutes. Beads were washed twice with $4 \mathrm{ml}$ 135 of 1xPBS and incubated in complete medium for 24 hours before viability was assessed.

\section{Optical vitrification assessment}

137 A volume of $4 \mathrm{ml}$ of each newly developed CPA solution and $\mathrm{Me}_{2} \mathrm{SO}$ at a concentration of $13860 \%$ and $70 \%(\mathrm{w} / \mathrm{v})$ was vitrified in a 12 -well plate by cooling samples at $-10^{\circ} \mathrm{C} / \mathrm{min}$ to $139160^{\circ} \mathrm{C}$. All solutions were then left at room temperature for warming and optical observation.

\section{Standard small volume vitrification protocol}

141 A traditional two-step small volume protocol was used to assess vitrification of AELC per se 142 and allow comparison to LT. Therefore $0.25 \mathrm{ml}$ settled beads were incubated in a $31.5 \%(\mathrm{w} / \mathrm{v}$ )

143 CPA solution in Nunc cryo-tubes (1.8 ml, Nunc, Loughborough, UK), first for five minutes at 144 room temperature and then for an additional five minutes at $0.5^{\circ} \mathrm{C}$ (tubes in ice-water). The 145 CPA concentration was increased to $63 \%(\mathrm{w} / \mathrm{v})$ using a $70 \%(\mathrm{w} / \mathrm{v})$ pre-cooled CPA solution 146 (at $0.5^{\circ} \mathrm{C}$ ). Samples were left on ice for five minutes and then plunged into liquid nitrogen. 
147 Samples were warmed for approximately eight minutes on ice until they reached a liquid state. By adding ice cold 1xPBS $\left(+\mathrm{Mg}^{2+}, \mathrm{Ca}^{2+}\right)$ the $\mathrm{CPA}$ concentration was reduced to $31.5 \%$

149 (w/v). Samples were left on ice for five minutes before washing twice with 4ml 1xPBS

$150\left(+\mathrm{Mg}^{2+}, \mathrm{Ca}^{2+}\right)$. Finally, AELC were incubated in complete media for 24 hours before 151 assessing viability.

\section{Liquidus Tracking}

153 The prototype Planer LT machine consists of a sample carrier with a magnetic stirrer which is 154 placed inside a Controlled Rate Freezer (Planer, Kryo 10, Series II chamber) and an inlet and outlet pump system [40]. All of these units are connected to a controller, which allows a completly automated cooling, mixing and addition and extraction process when using a single highly concentrated CPA solution. For the work presented here the peristaltic pumps were operated manually to allow for the use of differently concentrated CPA inlet solutions for both the cooling and warming process. A liquid volume of $450 \mathrm{ml}$ including $130 \mathrm{ml}$ of settled beads was used for each run, if not stated otherwise.

(i) LT cooling: The controlled rate freezer was first set on hold at $-20^{\circ} \mathrm{C}$ and then $-25^{\circ} \mathrm{C}$ until the sample reached a concentration of $32 \%(\mathrm{w} / \mathrm{v})$ at $-12^{\circ} \mathrm{C}$ and $40 \%(\mathrm{w} / \mathrm{v})$ at $-16^{\circ} \mathrm{C}$, respectively, by pumping in a 50\% CPA inlet solution. After that the freezer was set to $30{ }^{\circ} \mathrm{C}$ and a $60 \%(\mathrm{w} / \mathrm{v}) \mathrm{CPA}$ solution was used to increase the sample to $50 \%(\mathrm{w} / \mathrm{v})($ at $20^{\circ} \mathrm{C}$ ) and subsequently a $66 \%(\mathrm{w} / \mathrm{v})$ CPA solution was added to reach a final sample concentration of $64 \%(\mathrm{w} / \mathrm{v})\left(\right.$ at $\left.-20^{\circ} \mathrm{C}\right)$. CPA increase to $25 \%(\mathrm{w} / \mathrm{v})$ were carried out by addition only, increase to $64 \%(\mathrm{w} / \mathrm{v})$ was reached by operating both inlet and outlet pump simultaneously at a flow rate of $20 \mathrm{ml} / \mathrm{min}$. Then the freezer was set to $-160^{\circ} \mathrm{C}$ to cool the sample below the predicted glass transition temperature of about $-121^{\circ} \mathrm{C}$. Samples were held for a minimum of 10 minutes below $-125^{\circ} \mathrm{C}$ (Figure 2). The temperature was measured in the middle of the sample carrier, where cooling is slowest. 
(ii) LT warming: The sample carrier remained inside the freezer but with the liquid nitrogen supply shut off for slow warming to $-95^{\circ} \mathrm{C}$. For fast warming to $-40^{\circ} \mathrm{C}$ the sample carrier was placed outside the freezer at room temperature. For LT reversed warming, first $500 \mathrm{ml}$ of a $50 \%$, then a $40 \%$ and then a $30 \%(\mathrm{w} / \mathrm{v}) \mathrm{CPA}$ solution were pumped in at $20 \mathrm{ml} / \mathrm{min}$ to decrease the sample CPA concentration. Simultaneously sample solution was extracted at $20 \mathrm{ml} / \mathrm{min}$. The freezer holding temperature was increased from initially $-25^{\circ} \mathrm{C}$ to $-20^{\circ} \mathrm{C}$ and then $-15^{\circ} \mathrm{C}$ for 30 minutes. Finally, the freezer was set to $-10^{\circ} \mathrm{C}$ and $1 \mathrm{~L} 1 \times \mathrm{PBS}$ (at $20^{\circ} \mathrm{C}$ ) was added to decrease the sample CPA concentration to $0 \%$ (Figure 2).

\section{The temperature-concentration curve}

For each LT run the temperature/concentration (T/C) curve was determined by measuring the CPA concentration of the chamber outlet solution and by correlating this value to the sample temperature reached at the end of the extraction cycle. Thermocouples inserted into the inlet and outlet tube and inside the sample carrier were used to monitor the temperature. The refractive index (Digital Refractometer, Cole-Pamer Brix, 45.0 to 95.0\%, EW-02941-33) was used to determine the CPA concentration of the outlet solution based on a previously established standard curve [40].

\section{Filter system}

To maintain AELC beads (average diameter $(\mathrm{d})=450 \mu \mathrm{m}$ ) inside the sample carrier during CPA extraction and to avoid filter blockage, a plastic tube $(5 \mathrm{~cm}$ length, $\mathrm{d}=4 \mathrm{~cm})$ was covered from both ends with a $100 \mu \mathrm{m}$ mesh through which the outlet port was introduced. The filter was placed $1 \mathrm{~cm}$ away from the opening of the port - where the suction force was highest - to avoid the filter getting blocked by beads. 
196 To ensure that devitrification during warming was avoided, a finally sample CPA

197 concentration of $64 \%(\mathrm{w} / \mathrm{v})$ had to be reached, before the fast cooling process to below -

$198 \quad 121^{\circ} \mathrm{C}$ was started.

\section{Differential scanning calorimetry}

200 To establish the liquidus curve of the newly developed CPA solution, differential scanning

201 calorimetry (DSC) was used to determine the equilibrium melting point of increasing CPA

202 concentrations. The method has been described previously in detail [32].

\section{Statistics}

204 Statistical analyses were performed by Student's $t$-Test using Excel software.

205 Results

206 CPA development

207 (i) Viscosity - candidate CPA combinations

208 It was predicted that at least 40\% (w/v) penetrating CPAs and a maximum total concentration

209 of $70 \%$ (w/v) CPA should be used to obtain sufficient vitrification for large volumes and

210 slow cooling rates $\left(<10^{\circ} \mathrm{C} / \mathrm{min}\right)$ from previous feasibility studies [40]. By using the

211 observational viscosity test at $-40^{\circ} \mathrm{C}$ only four solutions were identified with a similar

212 viscosity to $70 \%$ (w/v) $\mathrm{Me}_{2} \mathrm{SO}$ when comparing (in increments of $10 \%$ ) combinations of

$213 \mathrm{Me}_{2} \mathrm{SO}, \mathrm{EG}$ and PG with the non-penetrating CPA glucose. All of these solutions contained

214 at least $40 \%(\mathrm{w} / \mathrm{v}) \mathrm{Me}_{2} \mathrm{SO}$, but only $10 \%(\mathrm{w} / \mathrm{v})$ glucose. The viscosity of another eight

215 solutions was sufficiently reduced for Liquidus Tracking through the substitution of $10 \%$

216 (w/v) of a penetrating CPA with methanol (Figure 1). Viscosity of CPA solutions of lowest

217 toxicity were additionally measured with a Bohlin ${ }^{\circledR} \mathrm{CVO}$ automated shear rheometer at $20^{\circ} \mathrm{C}$

218 displaying lowest viscosity for $70 \%(\mathrm{w} / \mathrm{v}) \mathrm{Me}_{2} \mathrm{SO}$ with $4.62 \mathrm{mPa} \cdot \mathrm{s}$ and highest viscosity for

$21940 \% \mathrm{Me}_{2} \mathrm{SO}$ with $20 \% \mathrm{EG}$ and $10 \%$ glucose (w/v) with $6.51 \mathrm{mPa} \cdot \mathrm{s}$ (Table 1$)$ 
To improve post-warming LT cell survival, non-penetrating sugars were added to $\mathrm{Me}_{2} \mathrm{SO}$,

which yielded poor AELC viability when used as a single CPA. Viability of AELC, incubated in $50 \%(w / v) \mathrm{Me}_{2} \mathrm{SO}$, decreased from $90 \%+/-2.15(\mathrm{n}=5)$ to $5.9 \%+/-3.6(\mathrm{n}=5)$.

The addition of $10 \%$ (w/v) of any sugar (glucose, fructose, raffinose, sucrose, trehalose) increased cell viability markedly by up to $50 \%$ although the final CPA concentration was increased to $60 \%(\mathrm{w} / \mathrm{v})$. The combination of glucose with another sugar $(5 \%(\mathrm{w} / \mathrm{v})$ each) did not significantly increase cell viability (Figure 3).

\section{(iii) Toxicities of low viscous CPA solutions}

Glucose was chosen as a CPA additive because it is readily available in large quantities, inexpensive and is clinically used. In a pre-screening toxicity test, solutions containing methanol $(10 \% \mathrm{w} / \mathrm{v})$ were generally more toxic to AELC than those without. Methanol was only well tolerated when the $\mathrm{Me}_{2} \mathrm{SO}$ concentration was equal or less than $30 \%$ (w/v) and with at least $10 \%(\mathrm{w} / \mathrm{v})$ EG. The toxicity test was repeated in more replicates with the five most

234 promising solutions. Additionally, these solutions were used to vitrify AELC in a standard small volume approach (Table 1, Figure 1). Both tests revealed the same order of performance with highest viability after treatment being obtained with $\mathrm{Me}_{2} \mathrm{SO} / \mathrm{EG} /$ glucose at a ratio of 4:2:1, followed by a combination of $\mathrm{Me}_{2} \mathrm{SO} / \mathrm{EG} /$ methanol/glucose at a ratio of 2:3:1:1 (Table 1). EG exhibited lower toxicity to AELC than $\mathrm{Me}_{2} \mathrm{SO}$ and PG when in combination with $\mathrm{Me}_{2} \mathrm{SO}$. However, a solution of only EG and glucose (6:1), defined too

240 viscous for LT (data not included in Table 1), exhibited significantly higher toxicity to AELC

241 than the combination of $\mathrm{EG}$, glucose and $\mathrm{Me}_{2} \mathrm{SO}$ with $50 \%$ versus $68 \%$ remaining viability 242 $(\mathrm{n}=5, \mathrm{p}<0.01)$. 
244 All five low toxicity solutions (Table 1 - solutions $>90 \%$ viability (test 1 )) vitrified (visual avoidance of ice formation) at a concentration of $70 \%$ (w/v), but only $\mathrm{Me}_{2} \mathrm{SO}$ and a combination of $\mathrm{Me}_{2} \mathrm{SO} / \mathrm{EG} / \mathrm{Glucose}$ in a ratio 5:1:1 vitrified (visual absence of ice) at $60 \%$ (w/v) (Figure 1). Those solutions that did not vitrify at 60\% (w/v) contained 20\% (w/v) or more EG. It was observed that ice disappearance during warming was slowest for a solution with $\mathrm{Me}_{2} \mathrm{SO} / \mathrm{EG} / \mathrm{Glucose}$ in a ratio of 4:2:1 (LTdeg), which was the only one that did not contain $10 \%(\mathrm{w} / \mathrm{v})$ methanol. Increasing the overall CPA concentration proportionately to $64 \%(\mathrm{w} / \mathrm{v})$ was found to be consistent with avoidance of visible ice during warming with LTdeg.

Standard small volume vitrification experiments were performed using the 5 CPA solutions of lowest toxicity and compared with the outcomes for toxicity testing without cryo-cooling at $0.5^{\circ} \mathrm{C}$. Recoveries of viability after $24 \mathrm{~h}$ culture for vitrification experiments post thaw were very low using $\mathrm{Me}_{2} \mathrm{SO}$ alone (around $1 \%$ ), whilst the best outcomes (53\%) were seen with LTdeg (Table 1, Figure 1). From these range setting experiments, LTdeg was chosen to take forward into the full LT investigations.

\section{Liquidus Tracking experiments}

\section{(i) Heat transfer measurements}

261 When the first LT runs were carried out, using $\mathrm{Me}_{2} \mathrm{SO}$ as a cryoprotectant, (with a freezer 262 cooling rate of $-1{ }^{\circ} \mathrm{C} /$ minute and a liquid volume of $\left.450 \mathrm{ml}\right)$, the temperature of the sample 263 inside the sample carrier was approximately $20^{\circ} \mathrm{C}$ higher than the temperature of the $\mathrm{Me}_{2} \mathrm{SO}$ 264 equilibrium melting point and $15^{\circ} \mathrm{C}$ higher than the predicted target temperature. To increase 265 the sample cooling rate by improving heat transfer, the freezer temperature was set up to $10^{\circ} \mathrm{C}$ below the predicted $\mathrm{Me}_{2} \mathrm{SO}$ liquidus curve. Although the CPA concentration inside the

267 outlet tube and the sample carrier is comparable, the solution inside the insulated outlet tube 
froze at sub-zero temperatures, as a result of its geometry and the resulting higher cooling rate. To avoid this, first infusions were carried out by operating the pumps manually, and the outlet was primed with $50 \%(\mathrm{w} / \mathrm{v})$ CPA when not in use. This allowed the freezer temperature to be set on hold at $-20^{\circ} \mathrm{C}$ and to maintain the sample/concentration curve close

272 to the liquids curve until a concentration of $25 \%(\mathrm{w} / \mathrm{v}) \mathrm{CPA}$ at $-8^{\circ} \mathrm{C}$ was reached, before 273 using inlet and outlet pump simultaneously (Figure 4).

\section{(ii) Machine delivered LT: $\mathrm{Me}_{2} \mathrm{SO}$ alone vs. new CPA solution}

Initial LT runs using the pump-driven mixing with a volume of $450 \mathrm{ml}$ (including $130 \mathrm{ml}$ of settled beads) using $\mathrm{Me}_{2} \mathrm{SO}$ as a single CPA resulted in no post-warming cell viability. When the newly developed CPA solution $\mathrm{Me}_{2} \mathrm{SO} / \mathrm{EG} /$ Glucose (4:2:1) was used, cell viability was increased to $40 \%(+/-7.7 \%)(n=3)$.

\section{(iii) Inhomogeneous "cell per bead" survival}

280 It was noted in preliminary studies by using fluorescence microscopy that some of the beads contained a high proportion of viable cells, while others contained almost exclusively dead cells after re-warming from LT. It was assumed that the effect was caused by the temperature difference within the sample carrier (e.g. colder at the carrier wall, bottom or surface and warmer at the centre). Viability up to a CPA concentration of $35-40 \%(w / v)$, reached at a temperature of $-15^{\circ} \mathrm{C}$, remained high and inhomogeneous AELC viability in beads was not observed. The inlet temperature was therefore maintained at $-15^{\circ} \mathrm{C}$, while increasing the CPA concentration from 35 to $64 \%$ (w/v), to avoid any potential CPA toxicity effects related to temperature differences within the system. Nevertheless, strong variations in viabilities between individual beads were observed. It was suspected that stirring the entire sample volume was inefficient, resulting in regions of poor CPA mixing and therefore potential ice nucleation. 
293 To achieve more homogenous mixing conditions, the original Planer stirrer, designed to hold

294 larger tissue constructs in the middle of the sample carrier while providing efficient CPA

295 homogenisation, was replaced with a simple propeller stirrer. By using the new propeller

296 stirrer, viabilities post LT were significantly improved from $38 \%+/-11.7$ to $77 \%+/-4.3$ (n=4

297 +/-SD) and strong variations in viable cell numbers between different individual beads were

298 no longer observed (Figure 5).

\section{9 (v) Cell density impacts cell survival}

300 Alginate encapsulated spheroids (AES) of high cell densities $\left(15 \times 10^{6}\right.$ cells $/ \mathrm{ml}$ of beads) were

301 less affected by LT treatment with new stirrer than AES of low cell density $\left(4 \times 10^{6}\right.$ cells per $\mathrm{ml} / \mathrm{beads})$ with viabilities of $57 \%+/-9.7$ and $11 \%+/-6.9$, respectively $(\mathrm{n}=17, \mathrm{p}<0.01)$. Both cultures were processed within the same run. Beads of either type were easily distinguished under the microscope, which made it possible to take images of single beads and determine the viability using the established FDA/PI method.

306 Although this procedure allowed testing of two populations of beads under exactly the same

307 conditions, cell number and protein synthesis could not be determined because beads of

308 different cell densities could not be physically separated. Thus, single run experiments were

309 carried out with batches of either high or low cell density beads. Again higher cell density

310 resulted in higher cell numbers, viability, albumin and alpha-fetoprotein production post LT

311 cooling with respect to the positive control. For cell densities of $17 \times 10^{6}$ and $20 \times 10^{6}$ cells $/ \mathrm{ml}$

312 of beads viability was $70 \%$ and $90 \%$, viable cell numbers were $67 \%$ and $96 \%$ and albumin

313 and alpha-fetoprotein release were $48 \%$ and $57 \%$, and $80 \%$ and $88 \%$, respectively (fraction of

314 the untreated control after 48 hours of post warming - Figure 6). 


\section{Discussion}

\section{Choice of CPA for LT}

317 We observed here that the pumps and stirrer of the semi-automated Liquidus Tracker are 318 impaired above a viscosity of approximately $900 \mathrm{mPa} \cdot \mathrm{s}\left(\mathrm{Me}_{2} \mathrm{SO}\right.$ at $\left.-40^{\circ} \mathrm{C}\right)$. Thus, viscosity

319 was identified as the first limiting factor for developing a new LT CPA solution. Dimethyl

320 sulfoxide $\left(\mathrm{Me}_{2} \mathrm{SO}\right)$, ethylene glycol (EG) and propylene glycol (PG) were selected as

321 penetrating CPAs based on their relatively low viscosity and their common use in vitrification protocols. Only four combinations (in increments of $10 \%$ ) of $\mathrm{Me}_{2} \mathrm{SO}, \mathrm{EG}$ and $\mathrm{PG}$ with $10 \%(w / v)$ glucose were of sufficiently low viscosity for our purpose. For this reason, viscosity was reduced by replacing $10 \%$ of a higher viscous penetrating CPA with methanol.

Monovalent alcohols are not commonly used in cryopreservation protocols, mostly due to their known high toxic effects on many biological systems. However, methanol has been used successfully in fish semen and embryo preservation [24,25,42]. In these applications, the concentration used was $10 \%$ or less, which justified the concentration used here. Although of general high toxicity, methanol was well tolerated when combined with EG and low amounts $(<=30 \% \mathrm{w} / \mathrm{v})$ of $\mathrm{Me}_{2} \mathrm{SO}$ and due to its high permeability [5] might be considered useful for some vitrification protocols.

332 Sugars are generally used to decrease the amount of penetrating CPAs while keeping similar

333 final CPA concentrations and glass-forming tendencies. When testing different sugars for our

334 LT CPA solutions, $\mathrm{Me}_{2} \mathrm{SO}$ was not replaced, but instead $10 \%$ (w/v) sugar was additionally included. The type of sugar used in our studies appeared to be irrelevant, which might suggest a general effect like reduced osmotic stress. It is known that sugars osmotically

337 reduced the cell volume, and therefore triggering reduced uptake of penetrating CPA, which

338 leads to less intracellular dehydration through CPAs and also reduced osmotic stress when 
339 CPAs are washed out. However, we have previously shown that AELC maintain high

340 viability after one-step addition and dilution of up to $40 \%(\mathrm{v} / \mathrm{v}) \mathrm{Me}_{2} \mathrm{SO}$ when carried out at

341 low temperatures [40]. The fact that AELC can support strong osmotic changes and that

342 toxicity is generally and strongly decreased at low temperatures (osmotic stress has been

343 suggested to increase at lower temperatures as the difference between transmembrane water

344 fluxes and movement of penetrating CPA increases [2]) might also indicate additional

345 effects, such as cell membrane stabilization or even some sort of biochemical toxicity

346 neutralisation comparable to that reported for reduced toxicity of formamide through the

347 addition of $\mathrm{Me}_{2} \mathrm{SO}$ [12]. For the semi-automated LT process osmotic stress is even further

348 reduces as lower concentrated CPA solution is continuously added while being mixed by a

349 stirrer. However, further work will be needed to assess the relevant importance of osmotic or

350 chemical toxicities within the overall context of LT.

351 Glucose was chosen for further LT studies for two reasons; firstly because it is clinically

352 available and inexpensive and for automated LT large CPA volumes are needed and secondly

353 because glucose has been reported to prevent irreversible binding of $\mathrm{Me}_{2} \mathrm{SO}$ to proteins [8].

354 EG is stated to be the least toxic CPA for hepatocyte virtification $[23,30]$ but for AELC in

355 LT, the combination of $\mathrm{Me}_{2} \mathrm{SO}(40 \% \mathrm{w} / \mathrm{v})$ and EG (20\% w/v) with $10 \%(\mathrm{w} / \mathrm{v})$ glucose,

356 resulted in significantly higher viability than either of the CPAs on its own with $10 \%(\mathrm{w} / \mathrm{v})$

357 glucose. This observation corresponds to previous findings from other authors in

358 chondrocytes and alginate encapsulated HepG2 and $\beta$-TC-cells, which suggest that

359 combinations of penetrating CPAs are less toxic than the use of a single CPA $[20,26,46]$. We

360 could find no explanation for the interaction between $\mathrm{EG}$ and $\mathrm{Me}_{2} \mathrm{SO}$, but both solutions are

361 also main components of the well-known and commercially available vitrification solutions

362 VS55 and M22 [12,14]. A similar composition of 22\% EG and $18 \% \mathrm{Me}_{2} \mathrm{SO}$ and $17.5 \%$ for 
both EG and $\mathrm{Me}_{2} \mathrm{SO}$ have also shown good results for the vitrification of cumulus cells [41] and equine embryos, respectively [35]. It is interesting, that - although developed to be first of low viscosity and second of low toxicity - our final chosen LT solution for AELC resembled those that are already commercially sold for other standard vitrification protocols.

367 We speculate that viscosity plays an important role in realizing an optimum between CPA 368 penetration and dehydration.

369 When developing new CPA mixtures, it is necessary to assess toxicity of cryoprotectants at the concentrations needed to vitrify. To get an estimation of the vitrification properties of the potential CPA solutions, $\mathrm{Me}_{2} \mathrm{SO}$ and the five CPA solutions of lowest toxicity to AELC were vitrified in small volumes and CPA solutions (without AELC) and were optically compared

373 for ice formation. Optical assessment of vitrification is only a semi-quantitative method compared to other physical measurements such as DSC, but it has been used in other studies $[18,50]$ as a direct method which can allow multiple conditions to be investigated at the same time. Whilst all solutions vitrified at $70 \%(\mathrm{w} / \mathrm{v}) \mathrm{CPA}$, only $\mathrm{Me}_{2} \mathrm{SO}$ and the mixture of $\mathrm{Me}_{2} \mathrm{SO} / \mathrm{EG} / \mathrm{glucose}$ with a ratio of 5:1:1 vitrified at 60\% (w/v) final CPA. One probable explanation why the other four solutions did not vitrify is the higher concentration of EG and methanol. EG has been described as a less effective vitrifier than $\mathrm{Me}_{2} \mathrm{SO}$ and $\mathrm{PG}[3]$ and methanol only vitrifies on its own under high pressure [6]. However, methanol seemed to have increased the rate at which ice melts during the warming phase, which could be advantageous for decreasing the amount of potential devitrification.

The top five low toxicity CPA solutions used to manually vitrify AELC in small volumes performed generally in the same order as they did in the toxicity studies. Reduced incubation time before plunging AELC into liquid nitrogen could be beneficial for solutions with higher concentrations of fast penetrating CPAs ( $\mathrm{Me}_{2} \mathrm{SO}$, methanol), and some solutions might vitrify 
at lower concentrations which would reduce CPA toxicity and increase viability. For the chosen set-up the solution of lowest toxicity was superior to the other solutions and proved to be an efficient vitrifier in the small volume protocol.

390 Final CPA concentrations for LT are of less risk for toxicity than for conventional

391 vitrification, as they are reached at very low temperatures $\left(<-30^{\circ} \mathrm{C}\right)$, at which $\mathrm{CPA}$ penetration and toxicity are suspected to be strongly reduced. However, at higher temperatures CPA toxicity is to be crucial for cell survival during the LT process. This would point to choosing the lowest toxicity CPA mixture instead of the best vitrifier for AELC preservation by LT.

\section{The semi-automated machine-delivered LT process}

397 Although LT allows for much slower cooling rates than conventional vitrification, cooling

398 rates can be still too slow in respect of practicality when large volumes are being cooled. In our system heat is transferred in two ways: conduction and convection. As the inlet is led through a tube of several meters that is kept within the freezer chamber, the temperature of the inlet solution was found to match that of the freezer chamber at the moment of addition.

402 The shape of the LT sample carrier (small surface area to volume ratio) is unfavourable for

403 fast cooling and warming rates by conduction. When the temperature difference between the 404 freezer chamber and sample is small, both conduction and convection have consequently 405 little impact on the overall sample temperature. Moreover, first CPA addition steps only 406 require small amounts of highly concentrated CPA solution to increase the sample 407 concentration. Thus, the initial temperature change by convection can be neglected. For our 408 work, neither sample volume nor the geometry of the sample carrier could be changed.

409 However reducing the freezer temperature from $5^{\circ} \mathrm{C}$ above to $20^{\circ} \mathrm{C}$ below the predicted 410 liquidus curve helped to increase the sample cooling rate, although the risk of outlet tube 
411 freezing had to be resolved. Using more inlet volume of lower concentrated CPA, thus

412 increasing convection, can further be used to increase the cooling rate but is logistically more

413 challenging. This type of approach for LT could be described as semi-automatic; the pumps

414 had to be operated by manual control to balance the relative volume exchanges as described;

415 however, the pumps allowed better overall control of solution movement than could be

416 achieved for example by manual decanting.

417 No viability of AELC was detected when $\mathrm{Me}_{2} \mathrm{SO}$ was used for semi-automated LT, but was 418 increased to approximately $40 \%$ viability when $\mathrm{Me}_{2} \mathrm{SO}$ was replaced with the newly

419 developed CPA solution, suggesting that CPA toxicity and/or osmotic injury was not fully

420 suppressed by the LT process. Inhomogeneous distribution of viable and dead cells between

421 alginate beads led to the assumption that temperature differences within the LT system had

422 caused this effect. The inlet temperature during the cooling process is much colder than the

423 sample temperature and there is also a temperature gradient across the sample carrier with

424 lower temperatures at the outside and higher temperatures on the inside of the sample

425 container. Inhomogeneous distribution of viable and dead cells was not noted for CPA

426 concentrations below $35 \%(\mathrm{w} / \mathrm{v})$, normally reached at $-15^{\circ} \mathrm{C}$. Consequently, the inlet and

427 sample solution temperature were maintained at $-15^{\circ} \mathrm{C}$, thus offsetting the temperature

428 difference inside the sample carrier, while the sample CPA concentration was increased to

$42964 \%(\mathrm{w} / \mathrm{v})$. However, strong variations in the number of viable cells per bead were still

430 detected, excluding temperature as the main factor for CPA toxicity.

431 Another possibility was that the method of stirring was the cause of this effect. The original

432 Planer stirrer was designed to operate alongside the sample carrier wall to avoid any

433 interference with larger, static constructs in the middle of the sample carrier. However, this

434 design exhibits strong differences across the sample carrier in respect to mixing behaviour. 
435 For example, AELC trapped between the static pedals and the moving part of the stirrer are

436 subject to stronger mixing and higher shear forces than AELC that are located at the centre of

437 sample carrier. To overcome these mixing differences a propeller stirrer was designed. As a

438 result viabilities were increased to around $80 \%$ and viable and non-viable cells were evenly

439 distributed across alginate beads. The inlet port being in close proximity to the Planer stirring

440 system is consistent with the theory that AELC located in the "intense mixing zone" and

441 close to the inlet of highly concentrated CPA, experienced high intra- and extracellular CPA

442 concentration differences and an enhanced mass transport across membranes as a result of

443 high kinetic energy caused by intensive stirring. Thus, chemical toxicity [12], dehydration

444 and osmotic stress [44] may have been reinforced through vicious mixing with this system,

445 which were improved by use of the propeller stirrer.

446 An interesting effect was seen when beads of varying cell densities were used for LT. Low

447 cell density beads tested in the same experiment, and therefore undergoing exactly the same

448 procedure as did high cell density beads, showed significantly reduced cell survival post

449 recovery. To measure cell numbers and protein release exclusively, experiments with beads

450 of the two different cell densities had to be independently repeated, but the outcomes were

451 the same. 3D cell cultures of higher cell density showed higher post-warming viability, cell

452 number and protein release. This is in accordance with previous observations: Higher cell

453 recovery of hepatocyte spheroids in comparison to single cell suspension following

454 cryopreservation has been reported by Lee and colleagues [27] and vitrification studies with

455 primary rat hepatocytes by Magalhães have shown better post-cryopreservation viability for

456 tissue-like culture than for single cells. They concluded that cell-to-cell contact is beneficial

457 in the maintenance of viability [29]. This might be due to higher cell activity in 3-D cell

458 cultures [37, 38], which has been linked to higher cell recovery following cryopreservation in 
single cell suspension [7]. It should be pointed out that the BAL system would require high

460 cell density (i.e. high total cell numbers) beads for clinical application [43].

461 In respect of shear forces created by the stirrer during LT, it can be expected that higher cell

462

463

464

465

466

467

468

469

470

471

472

473

474

475

476

477

478

479

480

481

482 density is beneficial, as the outer cells may provide protection to those located closer to the centre. This also applies in respect of excessive dehydration. In 3-dimensional cell constructs, water diffuses sequentially from one cell to its neighbour. Cells in the surface layer respond to osmotic changes in the extracellular medium; interior cells respond only to osmotic changes in cells of surfaces, and thus are exposed to slower rates of dehydration [28]. Shear stress is also likely to cause cell death by membrane disruption [36] and would account for a more homogenous distribution of viable and dead cells amongst beads when the propeller stirrer was used. However, with the current LT set up, shear stress would not seem to be a major injurious factor.

To further improve the LT system, it would be highly advantageous if the intracellular CPA and water concentration over the LT process could be monitored. For example, if it can be shown that CPA toxicity is negligible once CPA and water flux are (nearly) reversed and in the case that this happens within the temperatures range $\left(0\right.$ to $\left.-40^{\circ} \mathrm{C}\right)$ of $\mathrm{CPA}$ addition and reduction, LT protocols could be suitably adapted. The CPA concentration could then be increased at a higher temperature to ensure intracellular vitrification before cooling the sample. Once reached, the concentration needed to prevent devitrification during warming could be manipulated, for example, by using ice blocking agents [49] to minimise the risk of unwanted ice nucleation.

\section{Conclusion}

This work has shown that it is possible to use LT to vitrify large volumes of cell therapies such as AELC in the 3-D format. Further improvements to equipment technology, especially 
in respect to more automatization are required. An optimized stirring and CPA inlet system, as well as the use of $3 \mathrm{D}$ cultures of higher cell density $\left(>20 \times 10^{6}\right.$ cells $/ \mathrm{ml}$ beads $)$ may further increase post-warming viability and performance in the future. In theory, the LT volume could be further up-scaled by engineering a larger cell chamber with a scaled stirrer system.

\section{Acknowledgement}

488 We also thank Dr. Paul Matejtschuk and Kiran Malik (NIBSC, a Centre of the Health 489 Protection Agency) for enabling DSC analysis.

\section{$490 \quad$ Funding}

491 We thank Planer Plc, the Liver Group Charity and the Welcome Trust for funding this study.

\section{References}

493 [1] J.P. Acker, L.E. McGann, The role of cell-cell contact on intracellular ice formation, 1989. 19 (1989) 367-374.

[2] Y. Agca, J. Liu, J.J. McGrath, a T. Peter, E.S. Critser, J.K. Critser, Membrane permeability characteristics of metaphase II mouse oocytes at various temperatures in the presence of Me2SO., Cryobiology. 36 (1998) 287-300.

A. Baudot, L. Alger, P. Boutron, Glass-forming tendency in the system water-dimethyl sulfoxide, Cryobiology. 40 (2000) 151-158.

500 [4] M. Bokhari, R.J. Carnachan, N.R. Cameron, S.A. Przyborski, Culture of HepG2 liver cells on three dimensional polystyrene scaffolds enhances cell structure and function during toxicological challenge, J. Anat. 211 (2007) 567-576.

J.J. Brand, K.R. Diller, Application and theory of algal cryopreservation, Nov. Hedwigia. 79 (2004) 175-189.

[6] M.J.P. Brugmans, W.L. Vos, Competition between vitrification and crystallization of methanol at high pressure, J. Chem. Phys. 103 (1995) 2661-2669. 
[7] J.-S. Cho, S.-H. Chun, S.-J. Lee, I.-H. Kim, D.-I. Kim, Development of cell line preservation method for research and industry producing useful metabolites by plant cell culture, Biotechnol. Bioprocess Eng. 5 (2000) 372-378.

[8] P. Clark, G.M. Fahy, A.M. Karow, Factors influencing renal cryopreservation. II. Toxic effects of three cryoprotectants in combination with three vehicle solutions in nonfrozen rabbit cortical slices, Cryobiology. 21 (1984) 274-284.

[10] M.J. Dijkstra-Tiekstra, S. Hazelaar, E. Gkoumassi, M. Weggemans, J. de Wildt-Eggen, Comparison of cryopreservation bags for hematopoietic progenitor cells using a WBCenriched product, Transfus. Apher. Sci. 52 (2015) 187-193.

[11] E. Erro, J. Bundy, I. Massie, S.-A. Chalmers, A. Gautier, S. Gerontas, M. Hoare, P. Sharratt, S. Choudhury, M. Lubowiecki, I. Llewellyn, C. Legallais, B. Fuller, H. Hodgson, C. Selden, Bioengineering the liver: scale-up and cool chain delivery of the liver cell biomass for clinical targeting in a bioartificial liver support system, Biores. Open Access. 2 (2013) 1-11.

[12] G.M. Fahy, C. daMout, L. Tsonev, B. Khirabadi, P. Mehl, H.T. Meryman, Cellular injury associated with organ cryopreservation: chemical toxicity and cooling injury, in: J.J. Lemasters, C. Oliver (Eds.), Cell Biol. Trauma, CRC Press, Boca Raton, 1995.

[13] G.M. Fahy, B. Wowk, Principles of cryopreservation by vitrification, Methods Mol. Biol. 1257 (2015) 21-82.

[14] G.M. Fahy, B. Wowk, J. Wu, J. Phan, C. Rasch, A. Chang, E. Zendejas, Cryopreservation of organs by vitrification: perspectives and recent advances, Cryobiology. 48 (2004) 157-178. 
532

[15] J. Farrant, Mechanism of Cell Damage During Freezing and Thawing and its Prevention, Nature. 205 (1965) 1284-1287.

[16] R. Fleck, B. Fuller, Medicines from animal cell cultures, in: 2007.

[17] K.K. Fleming, A. Hubel, Cryopreservation of hematopoietic and non-hematopoietic stem cells, Transfus. Apher. Sci. 34 (2006) 309-315.

[18] X. He, E.Y.H. Park, A. Fowler, M.L. Yarmush, M. Toner, Vitrification by ultra-fast cooling at a low concentration of cryoprotectants in a quartz micro-capillary: A study using murine embryonic stem cells, Cryobiology. 56 (2008) 223-232.

[19] C.J. Hunt, Studies on cellular structure and ice location in frozen organs and tissues: The use of freeze-substitution and related techniques, Cryobiology. 21 (1984) 385402.

[20] N.M. Jomha, A.D.H. Weiss, J. Fraser Forbes, G.K. Law, J.A.W. Elliott, L.E. McGann, Cryoprotectant agent toxicity in porcine articular chondrocytes, Cryobiology. 61 (2010) 297-302.

[21] P. Kilbride, G.J. Morris, S. Milne, B. Fuller, J. Skepper, C. Selden, A scale down process for the development of large volume cryopreservation, Cryobiology. 69 (2014) $367-375$.

[22] C. Koshimoto, P. Mazur, Effects of cooling and warming rate to and from -70 degrees $\mathrm{C}$, and effect of further cooling from -70 to -196 degrees $\mathrm{C}$ on the motility of mouse spermatozoa, Biol. Reprod. 66 (2002) 1477-1484.

[23] L.L. Kuleshova, X.W. Wang, Y.N. Wu, Y. Zhou, H. Yu, Vitrification of encapsulated hepatocytes with reduced cooling and warming rates, Cryo Letters. 25 (2004) 241254.

[24] F. Lahnsteiner, The effect of internal and external cryoprotectants on zebrafish (Danio rerio) embryos, Theriogenology. 69 (2008) 384-396. 
557

558

559

560

561

562

563

564

565

566

567

568

569

570

571

572

573

574

575

576

577

578

579

580

581

[25] F. Lahnsteiner, N. Mansour, T. Weismann, The cryopreservation of spermatozoa of the burbot, Lota lota (Gadidae, Teleostei), Cryobiology. 45 (2002) 195-203.

[26] A. Lawson, H. Ahmad, A. Sambanis, Cytotoxicity effects of cryoprotectants as singlecomponent and cocktail vitrification solutions, Cryobiology. 62 (2011) 115-122.

[27] J.-H. Lee, D.-H. Jung, D.-H. Lee, J.-K. Park, S.-K. Lee, Effect of spheroid aggregation on susceptibility of primary pig hepatocytes to cryopreservation, Transplant. Proc. 44 (2012) 1015-1017.

[28] R.L. Levin, E.G. Cravalho, C.E. Huggins, Water transport in a cluster of closely packed erythrocytes at subzero temperatures, Cryobiology. 14 (1977) 549-558.

[29] R. Magalhães, B. Nugraha, S. Pervaiz, H. Yu, L.L. Kuleshova, Influence of cell culture configuration on the post-cryopreservation viability of primary rat hepatocytes, Biomaterials. 33 (2012) 829-836.

[30] R. Magalhães, X.W. Wang, S.S. Gouk, K.H. Lee, C.M. Ten, H. Yu, L.L. Kuleshova, Vitrification successfully preserves hepatocyte spheroids, Cell Transplant. 17 (2008) $813-828$.

[31] I. Massie, C. Selden, H. Hodgson, B. Fuller, Cryopreservation of encapsulated liver spheroids for a bioartificial liver: reducing latent cryoinjury using an ice nucleating agent, Tissue Eng. Part C. Methods. 17 (2011) 765-774.

[32] I. Massie, C. Selden, H. Hodgson, B. Fuller, Storage temperatures for cold-chain delivery in cell therapy: a study of alginate-encapsulated liver cell spheroids stored at $80^{\circ} \mathrm{c}$ or $-170^{\circ} \mathrm{c}$ for up to 1 year, Tissue Eng. Part C. Methods. 19 (2013) 189-195.

[33] I. Massie, C. Selden, H. Hodgson, B. Fuller, S. Gibbons, G.J. Morris, GMP Cryopreservation of Large Volumes of Cells for Regenerative Medicine: Active Control of the Freezing Process., Tissue Eng. Part C. Methods. 20 (2014) 1-46.

[34] J. Matheny, A.M. Karow, O. Carrier, Toxicity of dimethyl sulfoxide and magnesium 
as a function of temperature, Eur. J. Pharmacol. 5 (1969) 209-212.

583

584

585

586

587

588

589

590

591

592

593

594

595

596

597

598

599

600

601

602

603

604

605

606

[35] N. Oberstein, M.K. O’Donovan, J.E. Bruemmer, J. Seidel, E.M. Carnevale, E.L. Squires, Cryopreservation of equine embryos by open pulled straw, cryoloop, or conventional slow cooling methods, Theriogenology. 55 (2001) 607-613.

[36] J. Park, Z. Fan, C.X. Deng, Effects of shear stress cultivation on cell membrane disruption and intracellular calcium concentration in sonoporation of endothelial cells, J. Biomech. 44 (2011) 164-169.

[37] D.E. Pegg, The relevance of ice crystal formation for the cryopreservation of tissues and organs, Cryobiology. 60 (2010) S36-S44.

[38] D.E. Pegg, L. Wang, D. Vaughan, Cryopreservation of articular cartilage. Part 3: the liquidus-tracking method, Cryobiology. 52 (2006) 360-368.

[39] D.E. Pegg, L. Wang, D. Vaughan, C.J. Hunt, Cryopreservation of articular cartilage. Part 2: mechanisms of cryoinjury, Cryobiology. 52 (2006) 347-359.

[40] E. Puschmann, C. Selden, S. Butler, B. Fuller, Liquidus tracking: controlled rate vitrification for the cryopreservation of larger volumes and tissues., Cryo Letters. 35 (2014) 345-355.

[41] A.M. Saeed, M.J. Escribá, M.A. Silvestre, F. Garcia-Ximénez, Vitrification and rapidfreezing of cumulus cells from rabbits and pigs, Theriogenology. 54 (2000) 13591371.

[42] S. Seki, T. Kouya, R. Tsuchiya, D.M. Valdez, B. Jin, C. Koshimoto, M. Kasai, K. Edashige, Cryobiological properties of immature zebrafish oocytes assessed by their ability to be fertilized and develop into hatching embryos, Cryobiology. 62 (2011) 814.

[43] C. Selden, C.W. Spearman, D. Kahn, M. Miller, A. Figaji, E. Erro, J. Bundy, I. Massie, S.A. Chalmers, H. Arendse, A. Gautier, P. Sharratt, B. Fuller, H. Hodgson, Evaluation 
of encapsulated liver cell spheroids in a fluidised-bed bioartificial liver for treatment of ischaemic acute liver failure in pigs in a translational setting, PLoS One. 8 (2013).

609

610

611

612

613

614

615

616

617

618

619

620

621

622

623

624

625

626

627

628

629

630

631

[44] Y.S. Song, S. Moon, L. Hulli, S.K. Hasan, E. Kayaalp, U. Demirci, Microfluidics for cryopreservation, Lab Chip. 9 (2009) 1874-1881.

[45] G.N. Stacey, S. Dowall, Cryopreservation of primary animal cell cultures., in: Cryopreserv. Free. Protoc., 2007: pp. 271-281.

[46] C.A. Valdez, O. Abas Mazni, Y. Takahashi, S. Fujikawa, H. Kanagawa, Successful cryopreservation of mouse blastocysts using a new vitrification solution, J. Reprod. Fertil. 96 (1992) 793-802.

[47] L. Wang, D.E. Pegg, J. Lorrison, D. Vaughan, P. Rooney, Further work on the cryopreservation of articular cartilage with particular reference to the liquidus tracking (LT) method, Cryobiology. 55 (2007) 138-147.

[48] W.H. Weihe, The effect of temperature on the action of drugs, Annu. Rev. Pharmacol. 13 (1973) 409-425.

[49] B. Wowk, E. Leitl, C.M. Rasch, N. Mesbah-Karimi, S.B. Harris, G.M. Fahy, Vitrification enhancement by synthetic ice blocking agents, Cryobiology. 40 (2000) $228-236$.

[50] B. Wowk, E. Leitl, C.M. Rasch, N. Mesbah-Karimi, S.B. Harris, G.M. Fahy, Vitrification enhancement by synthetic ice blocking agents, Cryobiology. 40 (2000) $228-236$. 

AELC in $15 \mathrm{ml}$ Centrifuge tubes)

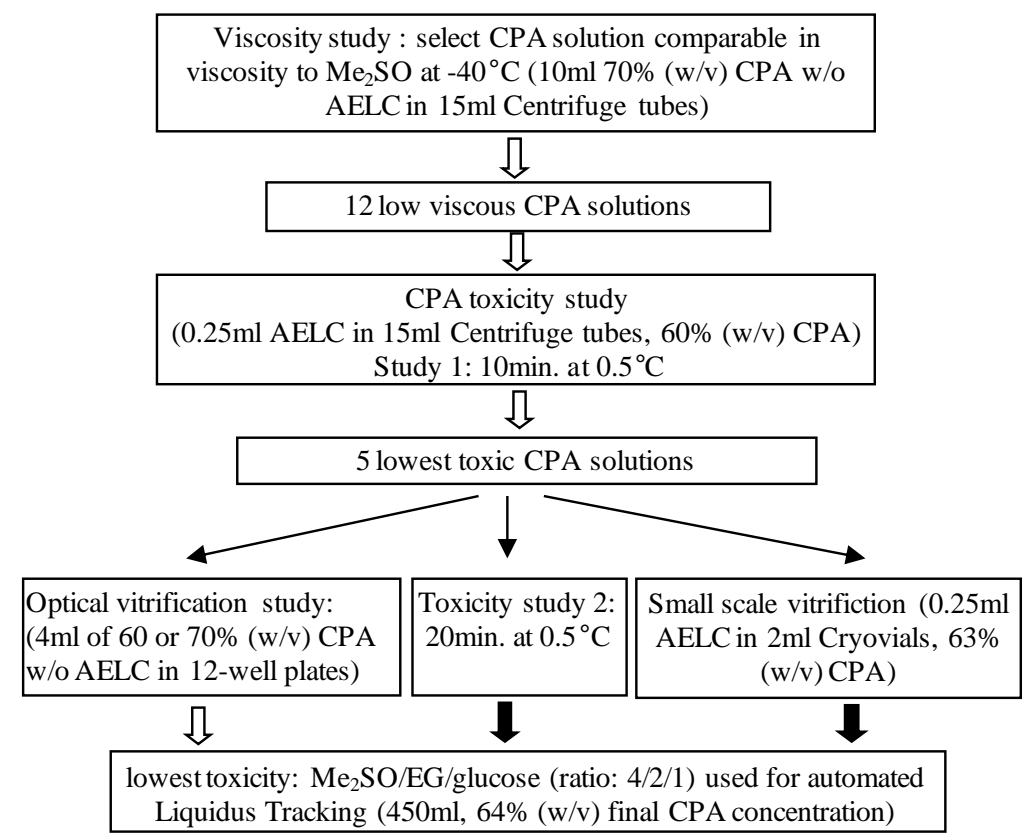

Figure 1: CPA development

638

Step 1: compare viscosity of combinations of $\mathrm{Me}_{2} \mathrm{SO}$, EG, PG, glucose (in increments of $10 \%(\mathrm{w} / \mathrm{v})$ ) and methanol $(10 \%(\mathrm{w} / \mathrm{v}))$ to $\mathrm{Me}_{2} \mathrm{SO}$ alone at $-40^{\circ} \mathrm{C}$. Select combinations with similar viscosity to $\mathrm{Me}_{2} \mathrm{SO}$. Step

640 2: test toxicity of low viscous CPA solutions on AELC $\left(10\right.$ minutes at $\left.0.5^{\circ} \mathrm{C}\right)$. Step 3: repeat step 3 for 5 lowest toxic CPA solutions for 20 minutes. Step 4: test 5 lowest toxic CPA solutions in a standard small

641 scale vitrification process. Step 6: visual observation of vitrification properties of 5 low toxic CPA

642 solution. Step 1-6: Incubation time and volumes were optimized for each test.

643 


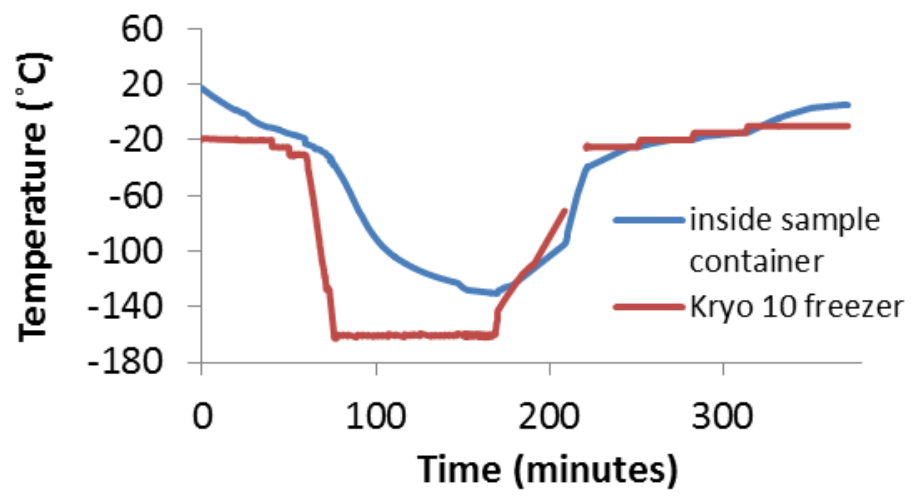

Figure 2: The LT cooling and warming profile

648 Temperature profile of the LT sample and the freezer were assessed by thermocouples being placed 649 inside the sample (blue line), and inside the freezer chamber (red line). When the sample reached a 650 temperature of $-95^{\circ} \mathrm{C}$ during warming, the sample container was placed outside the freezer at room 651 temperature (indicated by the interrupted red line at 200 minutes when the chamber was opened) for fast 652 initial warming to achieve a core sample temperature of $-40^{\circ} \mathrm{C}$. The freezer chamber temperature was 653 also set at $-40^{\circ} \mathrm{C}$, and the sample was returned to the chamber for the reverse $\mathrm{LT}$ process. To increase the 654 sample temperature further, the freezer temperature was set manually from initially $-25^{\circ} \mathrm{C}$ to $-20^{\circ} \mathrm{C}$ then $65515^{\circ} \mathrm{C}$ and finally $-10^{\circ} \mathrm{C}$, to keep the sample temperature above its liquidus curve and prevent freezing. 


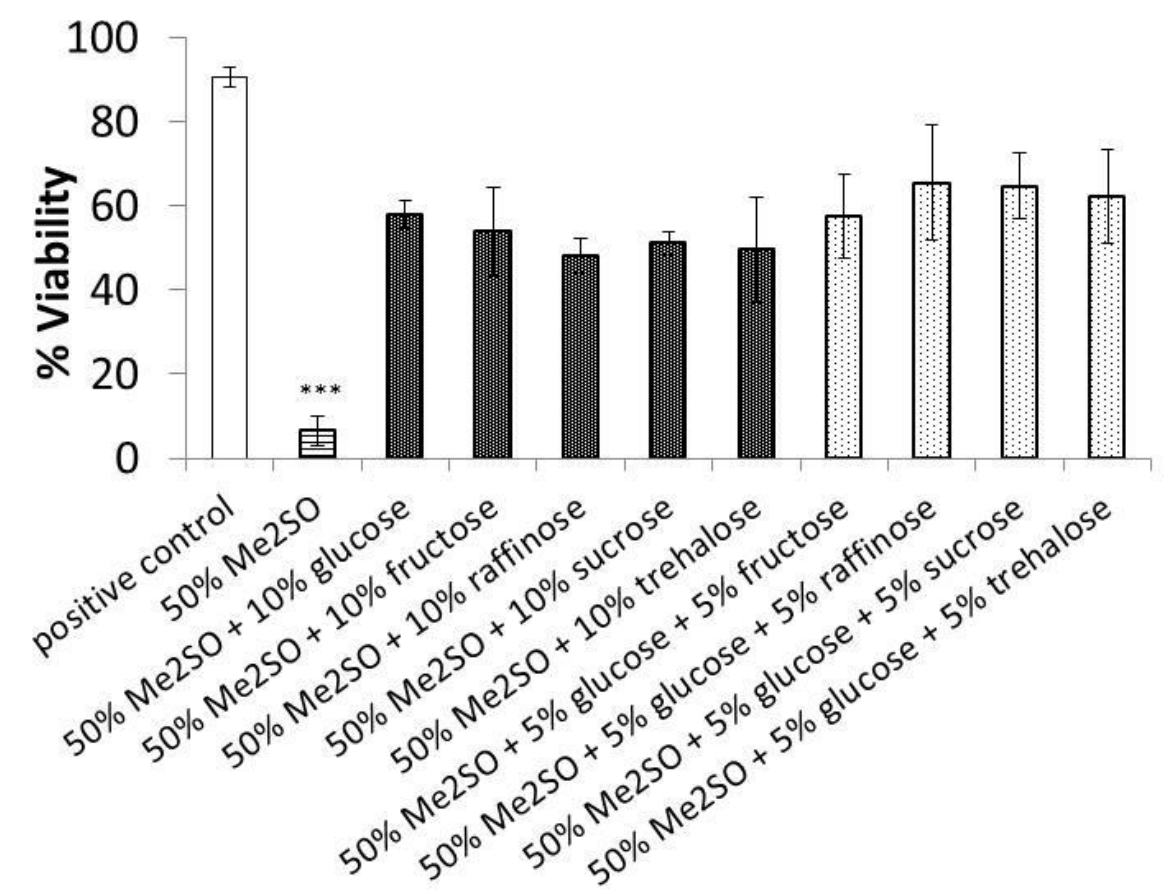

661

662 Figure 3: Sugars and sugar combination as non-penetrating CPA — effect in cell viability

663 AELC (0.25ml) were incubated in 50\% (w/v) $\mathrm{Me}_{2} \mathrm{SO}$ (white) or 50\% (w/v) $\mathrm{Me}_{2} \mathrm{SO}$ plus $10 \%$ (w/v) sugar, 664 either of one single sugar (grey) or two different sugars (light grey). AELC were incubated for 10 minutes 665 at $0.5^{\circ} \mathrm{C}$, using a step-wise CPA addition and reduction procedure. AELC were cultured for 24 hours in 666 complete media at $37^{\circ} \mathrm{C}$ before measuring viability by FDA/PI staining. Data were $n=5+/-\mathrm{SD}$. Viability 667 obtained with $50 \%$ (w/v) $\mathrm{Me}_{2} \mathrm{SO}$ was significantly lower than with solutions containing sugar, $668 * * * \mathbf{p}<\mathbf{0 . 0 0 1}$. 
669

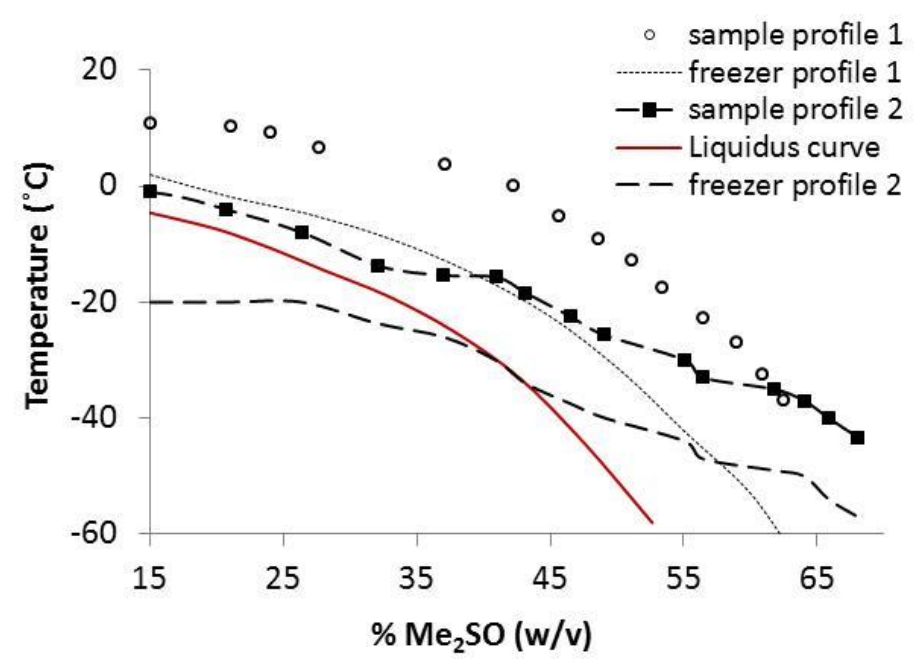

Figure 4: Freezer and sample cooling profile relative to the liquidus curve

672 Solutions with CPA concentrations below the liquidus curve (red) freeze, while those above remain liquid.

673 Liquidus Tracking: by keeping the sample temperature and CPA concentration just above the liquidus

674 curve, CPA toxicity was reduced and ice nucleation avoided. Freezer cooling profile 1 resulted in a

675 discrepancy of ${ }^{\sim} 15^{\circ} \mathrm{C}$ of the obtained sample profile (profile 1) to the expected profile (not shown) and was

676 approximately $20^{\circ} \mathrm{C}$ higher than the liquidus curve. To increase the sample cooling rate (sample profile 2)

677 the freezer temperature (freezer profile 2) was initially set to $-\mathbf{2 0}^{\circ} \mathrm{C}$ below the liquids curve. 
A.1

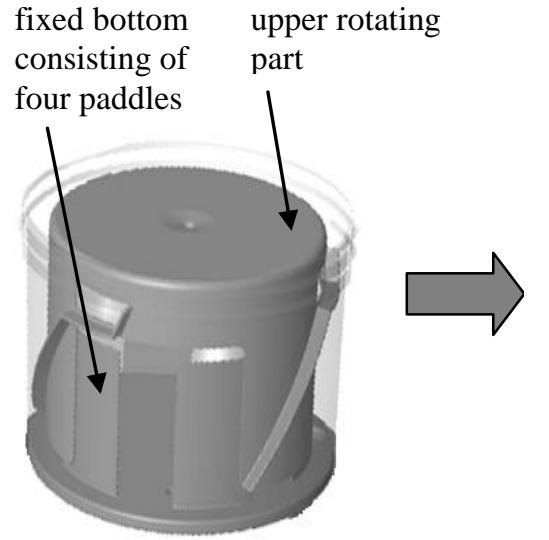

A.2

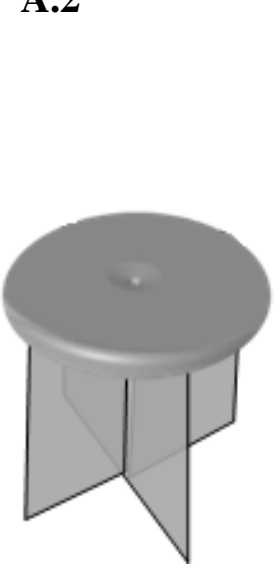

B.1

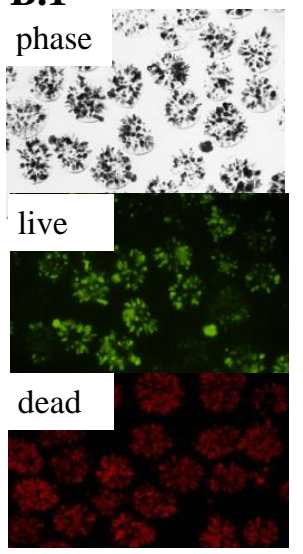

av. viability: $37 \%$
B. 2

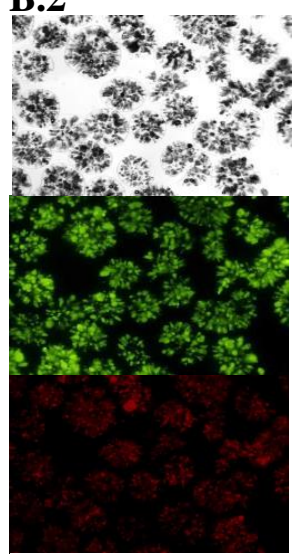

av. viability: $77 \%$

$680 \quad$ Figure 5: Planer stirrer versus propeller stirrer

681 A1: Planer stirrer - the paddles of the upper part move between the sample carrier wall and the paddles

682 of the bottom part - possibly creating strong differences in mixing behaviour and shear forces between 683 the sample carrier centre and on the outside. A2: Propeller stirrer - used for more homogenous mixing.

684 B1: AELC viability after using the Planer stirrer. B2: Propeller stirrer — viability was significantly 685 increased and bead to bead viability variation was reduced. The figure shows phase images, and images of 686 live (green, stained with FDA) and dead (red, stained with PI) cells.

687

688

689

690 Note: Figure 5- please print in color 

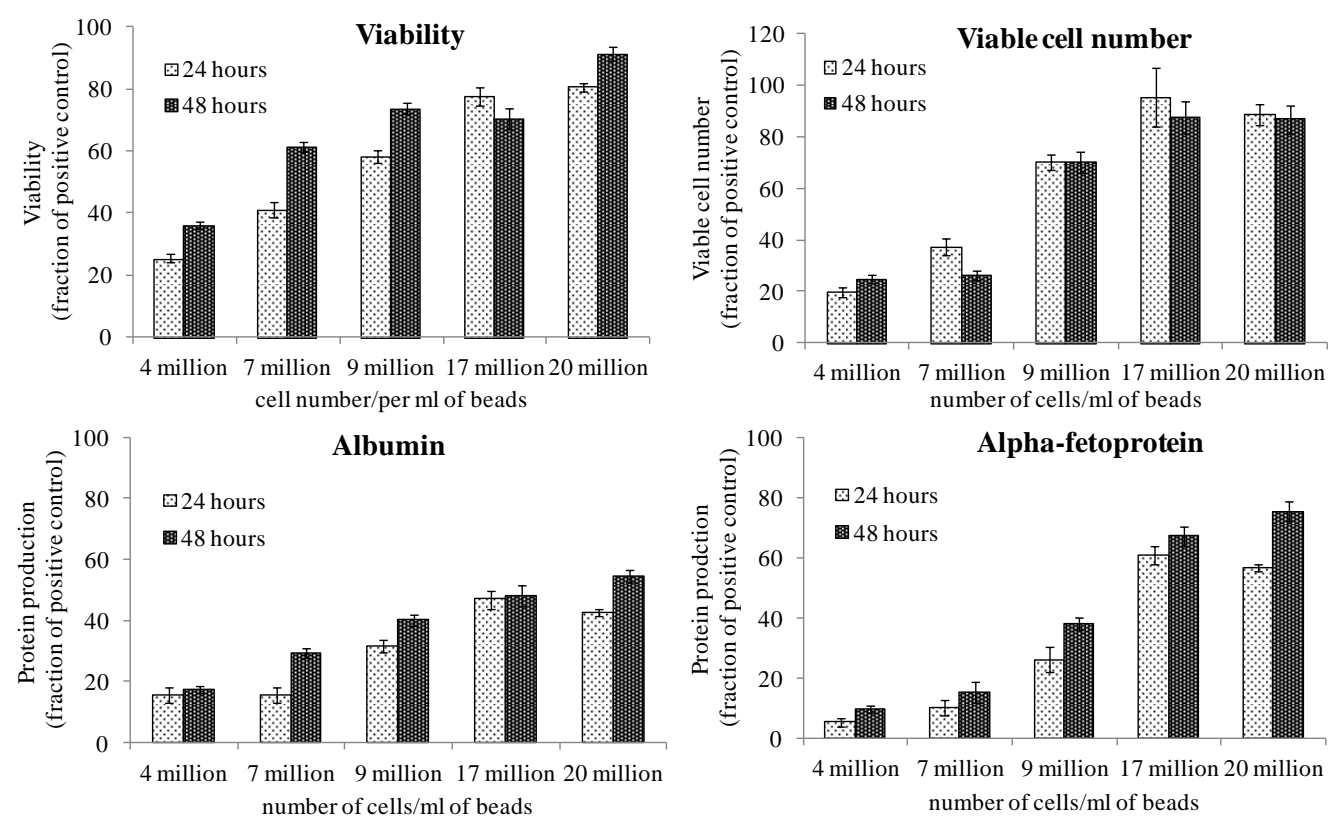

Figure 6: Impact of low and high cell densities on cell recovery

The higher the cell density was before the $\mathrm{LT}$ process $(4,7,9,17,20$ million cells $/ \mathrm{ml}$ of beads), the higher was the post-warming viability, viable cell number, albumin and alpha-fetoprotein synthesis. For each cell density one LT run was performed. Viability, cell number and protein production were measured in 5 replicates for each sample, and shown as means +/- SE . 130ml of beads in 450ml CPA were used. 